\title{
Exercise, but not quercetin, ameliorates inflammation, mitochondrial biogenesis, and lipid metabolism in skeletal muscle after strenuous exercise by high-fat diet mice
}

\author{
Soon Mi Kwon, Hee Geun Park, Jong Kui Jun and Wang Lok Lee* \\ Department of Sports Science, Chungnam National University, Daejeon, Korea
}

(Received: 2014/01/29, Revised: 2014/02/14, Published online: 2014/02/26)

[Purpose] The purpose of this study was to investigate whether moderate exercise and quercetin intake with a low fat diet contribute to inflammatory cytokine production, mitochondrial biogenesis, and lipid metabolism in skeletal muscle after strenuous exercise by high-fat diet mice. [Methods] Male C57BL/6 mice were randomly divided into four groups: (1) High-fat for 12 weeks and low-fat diet control $(\mathrm{C} ; \mathrm{n}=6)$; (2) high-fat diet for 12 weeks and low-fat diet with quercetin $(\mathrm{Q} ; \mathrm{n}=4)$; $(3)$ high-fat diet for 12 weeks and low-fat diet with exercise $(\mathrm{E} ; \mathrm{n}=4)$; or (4) high-fat diet for 12 weeks and low-fat diet with exercise and quercetin $(\mathrm{EQ} ; \mathrm{n}=5)$. Quercetin $(10 \mathrm{mg} / \mathrm{kg})$ was administered once per day, 5 day/week for 8 weeks. Exercise training was performed at moderate intensity for 8 weeks, 5 days/week for $30-60 \mathrm{~min} /$ day. Mice were subjected to a strenuous exercise bout of $60 \mathrm{~min}$ at a speed of $25 \mathrm{~m} / \mathrm{min}\left(\mathrm{VO}_{2} \max 85 \%\right)$ conducted as an exercise-induced fatigue just before sacrifice. [Results] As results, body weights were significantly different among the groups. Exercise training significantly reduced inflammatory cytokines after strenuous exercise in skeletal muscle of high-fat diet mice. Exercise training increased Tfam mRNA in the soleus muscle after strenuous exercise. Exercise training significantly decreased lipogenesis markers in skeletal muscle of obese mice after strenuous exercise. Moderate exercise significantly increased lipolysis markers in the tibialis anterior muscle. [Conclusion] These findings suggest that exercise training reduced inflammatory cytokine levels and improved mitochondrial biogenesis and lipid metabolism. However quercetin supplementation did not affect these parameters. Thus, long-term moderate exercise training has positive effects on obesity. [Keyword] obese; exercise; quercetin; inflammatory cytokine; mitochondrial biogenesis; skeletal muscle

\section{INTRODUCTION}

Obesity is a heightened state of inflammation. The adipose tissue is an active secretory organ that produces and releases a variety of proinflammatory [e.g., interleukin-lbeta (IL-1 $\beta$ ), leptin, tumor necrosis factor-alpha (TNF-a), IL-6] and anti-inflammatory proteins (e.g., IL-10, interleukin-1 receptor antagonist). TNF- $a$ is also over-expressed in adipose and muscle tissues of obese humans, and when administered exogenously leads to insulin resistance [1-3].

Quercetin exhibits antioxidative properties that are much stronger than those of vitamin $\mathrm{C}$ as well as anti-inflammatory [4,5] and anti-pathogenic properties [6]. Phenolic compounds selectively interfere with cytokine production and function. For example, quercetin and catechins inhibit TNF-a and IL-6, and simultaneously induce IL-10 release, and thus evoke the anti-inflammatory effect [7].

Exercise can have both positive and negative effects on inflammatory and redox status. While moderate activity may enhance immune function over sedentary levels, excessive, prolonged and high-intensity exercise may impair immune function [8]. Strenuous exercise increases production of several pro-and anti-inflammatory cytokines, endogenous cytokine inhibitors and chemokines [9]. Plasma IL-6 has been consistently shown to increase following acute knee-extensor, cycling, and resistance exercise [10]. Additionally, muscles release inflammatory cytokine during acute exercise, and levels can increase significantly [11]. Obesity and type 2 diabetes have been associated with a high-fat diet (HFD) and reduced mitochondrial mass and function [12]. Furthermore, peroxisome

\footnotetext{
* Corresponding author: Wanglok Lee, Tel. 82-42-821-6458, Fax. 82-42-823-0387, Email. leewl@cnu.ac.kr

(c)2014 The Korean Society for Exercise Nutrition
} 
proliferator-activated receptor gamma coactivator-1 (PGC-1a) is important in the development of diabetes mellitus [13] and a master regulator of oxidative phosphorylation gene expression and mitochondrial biogenesis [14].

Given the similarity in the structure of quercetin to resveratrol and other flavonoid derivatives that have been shown to increases PGC-1a leading to mitochondrial biogenesis, oxidative phosphorylation contributes to suppress lipid accumulation [15]. There is in vitro evidence of an effect of quercetin on the energetics of isolated mitochondria [16].

Low-intensity prolonged exercise training simultaneously increases the activity of skeletal muscle mitochondrial enzymes involved in the tricarboxylic acid cycle and fatty acid $\beta$ -oxidation [17]. Previous studies have demonstrated that PGC-1a is expressed in several tissues, including skeletal muscle and brown adipose tissue. PGC-1a increases mitochondria biogenesis and fatty acid oxidative metabolism [18]. In rats, PGC-1a mRNA and protein levels increase after a single bout of exercise as well as after several days of training [19].

It is generally accepted that the majority of the pleiotropic effects of long-term HFD is accompanied with changes in gene expression profiles. Several genes that encode enzymes or signal mediators involved in lipid and glucose metabolism respond to long-term HFD. For example, acyl-CoA oxidase (ACOX) and uncoupling protein-2 genes are altered in livers of long-term HFD mice, accompanied by an increase in the mRNA level of sterol regulatory element binding protein-1 (SREBP-1), the major transcriptional regulator for lipogenic genes [20].

Chronic exercise improves the capacity to utilize fatty acids by a coordinated upregulation of proteins involved in sarcolemmal uptake (fatty acid translocase), mitochondrial transport [carnitine palmitoyl transferase 1 (CPT1)] and $\beta$-oxidation (hydroxyacyl-coenzyme-A) of fatty acids [21]. Muscle AMPactivated protein kinase (AMPK) is stimulated during contraction, and may mediate multiple beneficial effects of exercise, specifically by increasing fatty acid oxidation and glucose uptake and promoting mitochondrial biogenesis. MalonylCoA is a potent allosteric inhibitor of CPT1, the rate-limiting enzyme that transfers long-chain acyl-CoA into mitochondria for $\beta$-oxidation [22].

Several studies have shown the effect of quercetin supplementation or exercise training separately, However, the synergistic effect of quercetin supplementation and exercise training has not been investigated after strenuous exercise as an oxidative stress. The aim of the present study was to investigate the effect of moderate exercise training and quercetin supplementation on inflammatory cytokine production, mitochondria biogenesis, and lipid metabolism after strenuous exercise in skeletal muscle of HFD mice.

\section{METHODS}

\section{Animals care and diet}

Male C57BL/6 mice (5-weeks-old) were purchased from Chungang Laboratory Animals (Seoul, Korea) and were housed in standard cages placed in a room at $22 \pm 2.0^{\circ}, 55 \pm 10 \%$ relative humidity, and a 12 hour-light/12hour-dark cycle. All mice consumed a commercial diet and tap water ad libitum for 1 week.

Mice were randomly divided into four groups:(1) HFD for 12 weeks and low-fat diet for 8 weeks control $(\mathrm{C} ; \mathrm{n}=6)$; (2) HFD for 12 weeks and low-fat diet for 8 weeks with quercetin (Q; $n=4)$; (3) HFD for 12 weeks and low-fat diet for 8 weeks with exercise $(E ; n=4)$; or (4) HFD for 12 weeks and low-fat diet for 8 weeks with exercise and quercetin (EQ; $\mathrm{n}=5$ ). The mice were weighed every 2 weeks during the experimental period. Commercially available dried quercetin dihydrate (Sigma, St. Louis, MO, USA; $\geq 98 \%$ purity by high-performance liquid chromatography) was used and dissolved in $50 \%$ propylene glycol. The control (C) and exercise (E) groups were orally administrated $100 \mu \mathrm{l}$ of propylene glycol as a vehicle. The quercetin $(\mathrm{Q})$ and exercise with quercetin (EQ) groups were orally gavaged with quercetin $(10 \mathrm{mg} / \mathrm{kg}$ body weight) dissolved in $50 \%$ propylene glycol. Each treatment was administered once per day, 5 days/week for 8 weeks. All treatments were performed $1 \mathrm{~h}$ after exercise.

Table 1. Rodent feed formulas.

\begin{tabular}{lcccc}
\hline \multirow{2}{*}{ Product } & \multicolumn{2}{c}{ High fat Diet } & \multicolumn{2}{c}{ Low fat Diet } \\
\cline { 2 - 5 } & gm $\%$ & $\mathrm{kcal} \%$ & $\mathrm{gm} \%$ & $\mathrm{kcal} \%$ \\
\hline Protein & 24 & 20 & 19.2 & 20 \\
Carbohydrate & 41 & 35 & 67.3 & 70 \\
Fat & 24 & 45 & 4.3 & 10 \\
Total & & 100 & & 100 \\
kcal/gm & 4.73 & & 3.85 & \\
\hline
\end{tabular}

High-fat diet (\#D12451, Orientbio Inc, Seoul, Korea), Low-fat diet (\#D12450, Orientbio Inc)

\section{Exercise protocol}

Exercise training was performed on a motor treadmill at moderate intensity for 8 weeks, 5 days/week for 30-60 $\mathrm{min} /$ day during the dark cycle. This exercise intensity corresponds to $65-70 \%$ of maximal oxygen uptake. Just before 
killing the mice, they performed $60 \mathrm{~min}$ of treadmill exercise at a speed of $25 \mathrm{~m} / \mathrm{min}\left(\mathrm{VO}_{2} \max 85 \%\right)$ to induce fatigue [23]. To control for any stress associated with the training protocol, animals in the control and quercetin groups were exposed to the same noise and handling as the exercise groups.

\section{Tissue preparation}

The animals were sacrificed by cervical dislocation 24 hours after strenuous exercise training. Skeletal muscle (tibialis anterior, soleus muscle) tissue were stored at $-70^{\circ} \mathrm{C}$ until analysis.

\section{$R N A$ extraction and semi quantitative reverse transcription-} polymerase chain reaction (RT-PCR)

Total RNA was isolated from the skeletal muscle tissue of each mouse using Trizol (Invitrogen, Carlsbad, CA, USA), and reverse-transcribed using the Superscript II kit (Invitrogen), according to the manufacturer's recommendations. The forward $(\mathrm{F})$ and reverse $(\mathrm{R})$ primers for the mice genes are shown in Table 2. The PCR was programmed as follows: $10 \mathrm{~min}$ at $94^{\circ} \mathrm{C}, 30-35$ cycles of $94^{\circ} \mathrm{C}$ for $30 \mathrm{~s}, 55^{\circ} \mathrm{C}$ for $30 \mathrm{~s} ; 72^{\circ} \mathrm{C}$ for $1 \mathrm{~min}$, and $10 \mathrm{~min}$ incubation at $72^{\circ} \mathrm{C}$. A $4 \mu \mathrm{l}$ aliquot of each PCR reaction was mixed with $1 \mu \mathrm{l}$ fivefold-concentrated loading buffer and was loaded onto $1 \%$ agarose gel containing ethidium bromide. PCR band density measurements were made with by Image Lab 4.0 (Bio-Rad, Hercules, CA, USA).The mRNA levels were normalized to the $\beta$-actin mRNA levels.

\section{Statistical methods}

The data was analyzed using of SPSS ver. 18.0 (SPSS, Inc., Chicago, IL, USA) to obtain means \pm standard deviations. Body weights among the four groups were analyzed by repeatedmeasures analysis of variance (ANOVA). To investigate the effects of moderate exercise and quercetin intake on inflammation, mitochondrial biogenesis, and lipid metabolism after strenuous exercise in skeletal muscle, all groups were com-
Table 2. Sequences of reverse transcription-polymerase chain reaction primers.

\begin{tabular}{|c|c|c|c|c|}
\hline Gene & & Sequences $\left(5^{\prime} \rightarrow 3^{\prime}\right)$ & $\operatorname{Tm}\left({ }^{\circ} \mathrm{C}\right)$ & Cycle \\
\hline IL-6 & $\begin{array}{l}\mathrm{F} \\
\mathrm{R}\end{array}$ & $\begin{array}{l}\text { TAGTCCTTCCTACCCCAATTTCC } \\
\text { TTGGTCCTTAGCCACTCCTTC }\end{array}$ & 58 & 35 \\
\hline TNF-a & $\begin{array}{l}\mathrm{F} \\
\mathrm{R}\end{array}$ & $\begin{array}{l}\text { CAAGGGACAAGGCTGCCCCG } \\
\text { TAGACCTGCCCGGACTCCGC }\end{array}$ & 64 & 35 \\
\hline MCP-1 & $\begin{array}{l}\mathrm{F} \\
\mathrm{R}\end{array}$ & $\begin{array}{l}\text { AGGTCCCTGTCATGCTTCTG } \\
\text { TCTGGACCCATTCCTTCTTG }\end{array}$ & 56 & 35 \\
\hline PGC-1a & $\begin{array}{l}\mathrm{F} \\
\mathrm{R}\end{array}$ & $\begin{array}{l}\text { TGGTGCCACCGCCAACCAAG } \\
\text { TGCCCCTGCCAGTCACAGGA }\end{array}$ & 64 & 35 \\
\hline Tfam & $\begin{array}{l}\mathrm{F} \\
\mathrm{R}\end{array}$ & $\begin{array}{l}\text { GGGGTCGCATCCCCTCGTCT } \\
\text { TCTGCCGGGCCTCCTTCTCC }\end{array}$ & 64 & 30 \\
\hline ACOX & $\mathrm{R}$ & $\begin{array}{l}\text { CGGCGCCGTCGAGAAATCGAG } \\
\text { ATGCCCTCGGTGCACAGAGTTT }\end{array}$ & 61 & 30 \\
\hline MCD & $\begin{array}{l}\mathrm{F} \\
\mathrm{R}\end{array}$ & $\begin{array}{l}\text { ATGGACGAGCTGCTGCGGCGA } \\
\text { GCGCGCCTGCTGGCGCAGCT }\end{array}$ & 54 & 40 \\
\hline $\mathrm{ACC}$ & $\begin{array}{l}\mathrm{F} \\
\mathrm{R}\end{array}$ & $\begin{array}{l}\text { ATGAGATCCAGCATGTCTGGCT } \\
\text { TGGAACATAGTGGTCTGCCATC }\end{array}$ & 59 & 30 \\
\hline SREBP & $\begin{array}{l}\mathrm{F} \\
\mathrm{R}\end{array}$ & $\begin{array}{l}\text { ATGCTCCAGCTCATCAACAACC } \\
\text { CGGTGAGGGCTGTGGCGCTG }\end{array}$ & 59 & 30 \\
\hline$\beta$-Actin & $\begin{array}{l}\mathrm{F} \\
\mathrm{R}\end{array}$ & $\begin{array}{l}\text { TCACCCACACTGTGCCCATCTACGA } \\
\text { CAGCGGAACCGCTCATTGCCAATGG }\end{array}$ & 65 & 27 \\
\hline
\end{tabular}

Each sequence is described as forward (F) and reverse (R). Genotech Inc., Seoul, Korea

pared with a two-way ANOVA. The differences were considered statistically significant at $a=0.05$.

\section{RESULTS}

\section{Body weight change}

Body weights were significantly different among the groups (group effect, $\mathrm{p}=0.001$; group $\times$ time interaction, $\mathrm{p}=0.001$ ). Exercise training had a significant effect on final body weight, whereas the quercetin supplement had no effect on final body weight. No interaction was detected between exercise and quercetin treatment for final body weight.

Table 3. Comparison of final body weight in each group (units: grams)

\begin{tabular}{|c|c|c|c|c|c|}
\hline Group & Initial body weight $(\mathrm{M} \pm \mathrm{SD})$ & Final body weight $(\mathrm{M} \pm \mathrm{SD})$ & Source & $\mathrm{F}$ & $\mathrm{p}$ \\
\hline $\mathrm{C}$ & $19.42 \pm 1.42$ & $35.50 \pm 5.38$ & & & \\
\hline Q & $19.88 \pm 1.36$ & $33.45 \pm 5.71$ & Exercise & 8.708 & $0.009^{* *}$ \\
\hline E & $19.62 \pm 0.93$ & $30.68 \pm 4.23$ & Quercetin & .909 & 0.355 \\
\hline EQ & $19.78 \pm 0.76$ & $29.42 \pm 4.45$ & Exercise $\times$ Quercetin & .214 & 0.650 \\
\hline
\end{tabular}

** $\mathrm{p}<0.01$. C, High-fat for 12 weeks and low-fat diet for 8 weeks control; Q, High-fat diet for 12 weeks and low-fat diet for 8 weeks with quercetin; E, high-fat diet for 12 weeks and low-fat diet for 8 weeks with exercise; EQ, high-fat diet for 12 weeks and low-fat diet for 8 weeks with exercise and quercetin. All values are means \pm standard deviations (SDs). 


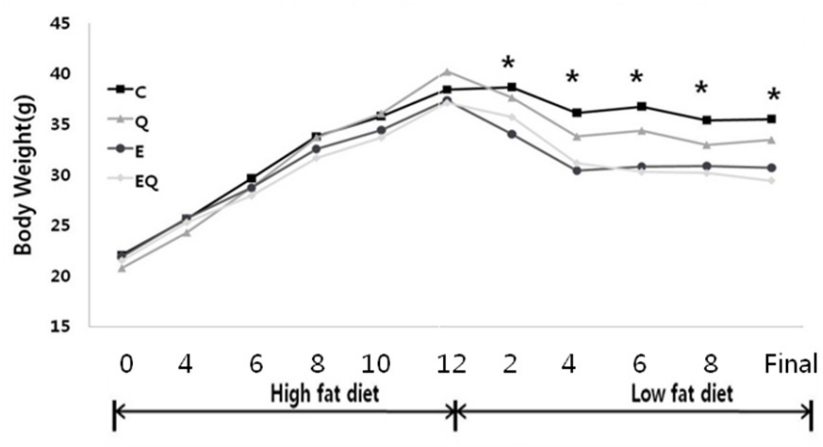

Fig. 1. Changes in body weights in the groups; C, high-fat for 12 weeks and low-fat diet for 8 weeks control; Q, high-fat diet for 12 weeks and low-fat diet for 8 weeks with quercetin; E, high-fat diet for 12 weeks and low-fat diet for 8 weeks with Exercise; EQ, high-fat diet for 12 weeks and low-fat diet for 8 weeks with exercise and quercetin.

\section{Inflammatory cytokines}

\section{IL-6 mRNA expression}

Exercise training had a significant effect on IL-6 mRNA expression in tibialis anterior muscle. However, quercetin supplementation had no effect on IL-6 mRNA expression in tibialis anterior and soleus muscles. The interactions between exercise and quercetin treatment were not significantly different for IL-6 mRNA expression in the tibialis anterior and soleus muscles (Table 4 and Fig. 2).

Table 4. Interleukin-6 (IL-6) mRNA expression in skeletal muscle.

\begin{tabular}{ccclcc}
\hline Sample & Group & $\mathrm{M} \pm \mathrm{SD}$ & \multicolumn{1}{c}{ Source } & $\mathrm{F}$ & $\mathrm{p}$ \\
\hline \multirow{4}{*}{ Tibialis } & $\mathrm{C}$ & $0.90 \pm 0.60$ & & & \\
anterior & $\mathrm{Q}$ & $0.54 \pm 0.45$ & Exercise & 6.03 & $0.03^{*}$ \\
& $\mathrm{E}$ & $0.29 \pm 0.56$ & Quercetin & 1.26 & 0.28 \\
& $\mathrm{EQ}$ & $0.22 \pm 0.60$ & & \\
& $\mathrm{C}$ & $0.36 \pm 0.06$ & & & \\
& $\mathrm{Q}$ & $0.31 \pm 0.07$ & Exercise $\times$ Quercetin & 0.59 & 0.46 \\
Soleus & $\mathrm{E}$ & $0.31 \pm 0.07$ & Quercetin & 0.99 & 0.33 \\
& $\mathrm{EQ}$ & $0.31 \pm 0.06$ & & 0.70 & 0.42 \\
& & & & \\
\hline
\end{tabular}

$* \mathrm{p}<0.05$. C, High-fat for 12 weeks and low-fat diet for 8 weeks control; Q, high-fat diet for 12 weeks and low-fat diet for 8 weeks with quercetin; E, high-fat diet for 12 weeks and low-fat diet for 8 weeks with Exercise; EQ, high-fat diet for 12 weeks and low-fat diet for 8 weeks with exercise and quercetin. All values are means \pm standard deviation (SDs) of relative density units using $\beta$-actin as the control.

\section{TNF-a mRNA expression}

Exercise training had significant effects on TNF-a mRNA expression in tibialis anterior and soleus muscle, whereas quercetin did not. The interactions between exercise and quercetin treatment were not significantly different in TNF-a mRNA expression in tibialis anterior and soleus muscle (Table 5 and Fig. 2).
Table 5. Tumor necrosis factor- $a$ (TNF- $\alpha$ ) mRNA expression in skeletal muscle.

\begin{tabular}{ccclcl}
\hline Sample & Group & $\mathrm{M} \pm \mathrm{SD}$ & \multicolumn{1}{c}{ Source } & $\mathrm{F}$ & $\mathrm{p}$ \\
\hline \multirow{4}{*}{ Tibialis } & $\mathrm{C}$ & $0.45 \pm 0.11$ & & & \\
anterior & $\mathrm{Q}$ & $0.42 \pm 0.15$ & Exercise & 51.45 & $.001^{* *}$ \\
& $\mathrm{E}$ & $0.17 \pm 0.04$ & Quercetin & 1.16 & 0.30 \\
& $\mathrm{EQ}$ & $0.11 \pm 0.02$ & & & \\
& $\mathrm{C}$ & $1.20 \pm 0.34$ & & & \\
& $\mathrm{Q}$ & $1.00 \pm 0.13$ & Exercise $\times$ Quercetin & 0.10 & 0.76 \\
Soleus & $\mathrm{E}$ & $0.75 \pm 0.06$ & Quercetin & 11.47 & $.001^{* *}$ \\
& $\mathrm{EQ}$ & $0.70 \pm 0.17$ & & 1.10 & 0.31 \\
& & & & \\
\hline
\end{tabular}

** $\mathrm{p}<0.01$.C, High-fat for 12 weeks and low-fat diet for 8 weeks control; Q, high-fat diet for 12 weeks and low-fat diet for 8 weeks with quercetin; E, high-fat diet for 12 weeks and low-fat diet for 8 weeks with exercise; EQ, high-fat diet for 12 weeks and low-fat diet for 8 weeks with exercise and quercetin. All values are means \pm standard deviations (SDs) of relative density units using $\beta$-actin as the control .

Monocyte chemoattractant protein-1 (MCP-1) mRNA expression Exercise training had significant effects on MCP-1 mRNA expression in the tibialis anterior and soleus muscle, whereas quercetin supplementation did not. The interactions between exercise and quercetin treatment were not significantly

Table 6. Monocyte chemoattractant protein-1 (MCP-1) mRNA expression in skeletal muscle.

\begin{tabular}{|c|c|c|c|c|c|}
\hline Sample & Group & $\mathrm{M} \pm \mathrm{SD}$ & Source & $\mathrm{F}$ & $\mathrm{p}$ \\
\hline \multirow{5}{*}{$\begin{array}{l}\text { Tibialis } \\
\text { anterior }\end{array}$} & $\mathrm{C}$ & $1.58 \pm 0.75$ & \multirow{5}{*}{$\begin{array}{l}\text { Exercise } \\
\text { Quercetin } \\
\text { Exercise } \times \text { Quercetin }\end{array}$} & \multirow{5}{*}{$\begin{array}{l}5.99 \\
3.46 \\
3.23\end{array}$} & \multirow{5}{*}{$\begin{array}{l}0.03^{*} \\
0.08 \\
0.10\end{array}$} \\
\hline & Q & $0.72 \pm 0.22$ & & & \\
\hline & $\mathrm{F}$ & $059+035$ & & & \\
\hline & & (3.0. & & & \\
\hline & EQ & $0.57 \pm 0.42$ & & & \\
\hline \multirow{5}{*}{ Soleus } & C & $0.44 \pm 0.04$ & \multirow{5}{*}{$\begin{array}{l}\text { Exercise } \\
\text { Quercetin } \\
\text { Exercise } \times \text { Quercetin }\end{array}$} & \multirow{5}{*}{$\begin{array}{l}5.24 \\
0.57 \\
2.90\end{array}$} & \multirow{5}{*}{$\begin{array}{l}0.04^{*} \\
0.46 \\
0.11\end{array}$} \\
\hline & Q & $0.39 \pm 0.11$ & & & \\
\hline & $E$ & $0.23 \pm 0.07$ & & & \\
\hline & & & & & \\
\hline & EQ & $0.36 \pm 0.19$ & & & \\
\hline
\end{tabular}

$* \mathrm{p}<0.05$.C, High-fat for 12 weeks and low-fat diet for 8 weeks control; Q, high-fat diet for 12 weeks and low-fat diet for 8 weeks with quercetin; E, high-fat diet for 12 weeks and low-fat diet for 8 weeks with exercise; EQ, high-fat diet for 12 weeks and low-fat diet for 8 weeks with exercise and quercetin. All values are expressed as means \pm standard deviations (SDs) of relative density units using $\beta$-actin as the control.

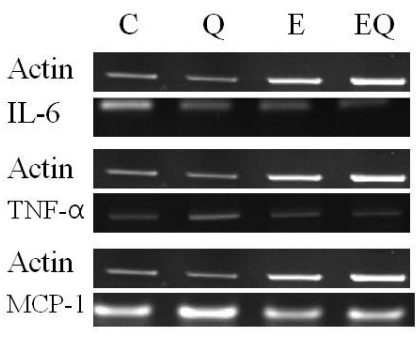

Tibialis anterior

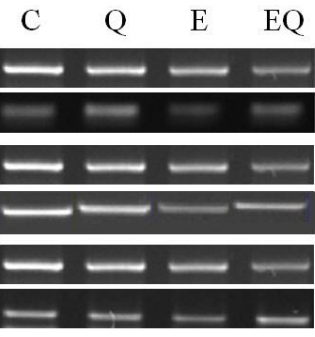

Soleus
Fig. 2. Reverse transcription polymerase chain reaction analysis of the expression of inflammatory cytokines in skeletal muscle. 
different for MCP-1 mRNA expression in the tibialis anterior and soleus muscle (Table 6 and Fig. 2).

\section{Mitochondrial biogenesis}

Peroxisome proliferator-activated receptor-gamma coactivator 1 (PGC-1) mRNA expression

Exercise training had significant effects on PGC-1 mRNA expression in soleus muscle. However, quercetin supplementation had no effect. Interactions between exercise and quercetin treatment were not significantly different for PGC-1 mRNA expression in tibialis anterior and soleus muscles (Table 7 and Fig. 3).

Table 7. Peroxisome proliferator-activated receptor-gamma coactivator 1 (PGC-1) mRNA expression of in skeletal muscle.

\begin{tabular}{|c|c|c|c|c|c|}
\hline Sample & Group & $\mathrm{M} \pm \mathrm{SD}$ & Source & $\mathrm{F}$ & $\mathrm{p}$ \\
\hline \multirow{5}{*}{$\begin{array}{l}\text { Tibialis } \\
\text { anterior }\end{array}$} & $\mathrm{C}$ & $1.22 \pm 0.46$ & \multirow{5}{*}{$\begin{array}{l}\text { Exercise } \\
\text { Quercetin } \\
\text { Exercise } \times \text { Quercetin }\end{array}$} & \multirow{5}{*}{$\begin{array}{l}1.75 \\
0.45 \\
0.51\end{array}$} & \multirow{5}{*}{$\begin{array}{l}0.21 \\
0.51 \\
0.49\end{array}$} \\
\hline & Q & $1.63 \pm 1.16$ & & & \\
\hline & & & & & \\
\hline & $\mathrm{E}$ & $1.82 \pm 0.22$ & & & \\
\hline & EQ & $1.81 \pm 0.23$ & & & \\
\hline \multirow{5}{*}{ Soleus } & $\mathrm{C}$ & $0.85 \pm 0.16$ & \multirow{5}{*}{$\begin{array}{l}\text { Exercise } \\
\text { Quercetin } \\
\text { Exercise } \times \text { Quercetin }\end{array}$} & \multirow{5}{*}{$\begin{array}{l}10.85 \\
1.54 \\
0.57\end{array}$} & \multirow{5}{*}{$\begin{array}{l}0.01^{*} \\
0.23 \\
0.46\end{array}$} \\
\hline & Q & $0.91 \pm 0.09$ & & & \\
\hline & $F$ & & & & \\
\hline & $\mathrm{E}$ & $1.16 \pm 0.30$ & & & \\
\hline & EQ & $1.40 \pm 0.38$ & & & \\
\hline
\end{tabular}

$* \mathrm{p}<0.05$. C, High-fat for 12 weeks and low-fat diet for 8 weeks control; Q, high-fat diet for 12 weeks and low-fat diet for 8 weeks with quercetin; E, high-fat diet for 12 weeks and low-fat diet for 8 weeks with exercise; EQ, high-fat diet for 12 weeks and low-fat diet for 8 weeks with exercise and quercetin. All values are means \pm standard deviations (SDs) of relative density units using $\beta$-actin as the control.

\section{Tfam mRNA expression}

Exercise training and quercetin supplement did not significantly affect the mitochondrial transcription factor Tfam mRNA expression in tibialis anterior and soleus muscle.

Table 8. Tfam mRNA expression in skeletal muscle.

\begin{tabular}{|c|c|c|c|c|c|}
\hline Sample & Group & $\mathrm{M} \pm \mathrm{SD}$ & Source & $\mathrm{F}$ & $\mathrm{p}$ \\
\hline \multirow{4}{*}{$\begin{array}{l}\text { Tibialis } \\
\text { anterior }\end{array}$} & $\mathrm{C}$ & $0.90 \pm 0.40$ & \multirow{4}{*}{$\begin{array}{l}\text { Exercise } \\
\text { Quercetin } \\
\text { Exercise } \times \text { Quercetin }\end{array}$} & \multirow{4}{*}{$\begin{array}{l}3.65 \\
0.05 \\
0.72\end{array}$} & \multirow{4}{*}{$\begin{array}{l}0.08 \\
0.83 \\
0.41\end{array}$} \\
\hline & Q & $1.04 \pm 0.19$ & & & \\
\hline & E & $1.27 \pm 0.18$ & & & \\
\hline & EQ & $1.18 \pm 0.22$ & & & \\
\hline \multirow{5}{*}{ Soleus } & $\mathrm{C}$ & $0.91 \pm 0.26$ & \multirow{5}{*}{$\begin{array}{l}\text { Exercise } \\
\text { Quercetin } \\
\text { Exercise } \times \text { Quercetin }\end{array}$} & \multirow{5}{*}{$\begin{array}{l}0.81 \\
0.06 \\
0.00\end{array}$} & \multirow{5}{*}{$\begin{array}{l}0.38 \\
0.82 \\
0.97\end{array}$} \\
\hline & $\mathrm{Q}$ & $0.96 \pm 0.37$ & & & \\
\hline & $\mathrm{F}$ & $111+031$ & & & \\
\hline & $\mathrm{E}$ & $1.11 \pm 0.31$ & & & \\
\hline & EQ & $1.17 \pm 0.81$ & & & \\
\hline
\end{tabular}

C, High-fat for 12 weeks and low-fat diet for 8 weeks control; Q, high-fat diet for 12 weeks and low-fat diet for 8 weeks with quercetin; E, high-fat diet for 12 weeks and low-fat diet for 8 weeks with exercise; EQ, high-fat diet for 12 weeks and low-fat diet for 8 weeks with exercise and quercetin. All values are expressed as means \pm standard deviations (SDs)of relative density units using $\beta$-actin as the control.

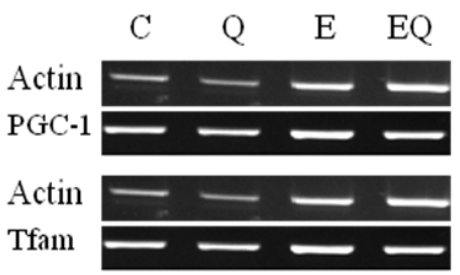

Tibialis anterior

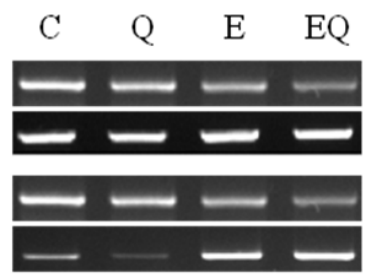

Soleus
Fig. 3. Reverse transcription polymerase chain reaction analysis of the expression of mitochondria biogenesis in skeletal muscle.

The interactions between exercise and quercetin treatment were not significantly different for Tfam mRNA expression in tibialis anterior and soleus muscle (Table 8 and Fig. 3).

\section{Lipid metabolism}

\section{Lipolysis marker ; \\ ACOX mRNA expression}

Exercise training had significant effects on ACOX mRNA expression in tibialis anterior muscle, whereas quercetin supplementation did not. The interactions between exercise and quercetin treatment were not significantly different in ACOX mRNA expression in tibialis anterior and soleus muscle (Table 9 and Fig. 4).

Table 9. ACOX mRNA expression in skeletal muscle.

\begin{tabular}{ccclcl}
\hline Sample & Group & $\mathrm{M} \pm \mathrm{SD}$ & \multicolumn{1}{c}{ Source } & $\mathrm{F}$ & $\mathrm{p}$ \\
\hline & $\mathrm{C}$ & $1.22 \pm 0.42$ & & & \\
Tibialis & $\mathrm{Q}$ & $1.17 \pm 0.16$ & Exercise & 37.11 & $.001^{* *}$ \\
anterior & $\mathrm{E}$ & $2.46 \pm 0.59$ & Quercetin & 0.02 & 0.88 \\
& $\mathrm{EQ}$ & $2.58 \pm 0.56$ & & & \\
& $\mathrm{C}$ & $0.31 \pm 0.10$ & & & \\
& $\mathrm{Q}$ & $0.89 \pm 0.52$ & Exercise & 3.67 & 0.80 \\
Soleus & $\mathrm{E}$ & $1.03 \pm 0.78$ & Quercetin & 1.79 & 0.20 \\
& $\mathrm{EQ}$ & $1.10 \pm 0.59$ & & 1.10 & 0.31 \\
\hline
\end{tabular}

** $\mathrm{p}<0.01$. C, High-fat for 12 weeks and low-fat diet for 8 weeks control; Q, high-fat diet for 12 weeks and low-fat diet for 8 weeks with quercetin; E, high-fat diet for 12 weeks and low-fat diet for 8 weeks with exercise; $\mathrm{EQ}$, high-fat diet for 12 weeks and low-fat diet for 8 weeks with exercise and quercetin. All values are expressed as means \pm standard deviations (SDs) of relative density units using $\beta$-actin as the control.

\section{Lipogenesis markers}

\section{$M C D$ mRNA expression}

Exercise training had a significant effect on MCD mRNA expression in tibialis anterior muscle, whereas quercetin supplementation did not. The interactions between exercise and quercetin treatment were not significantly different in MCD mRNA expression in the tibialis anterior and soleus muscle (Table 10 and Fig. 4). 
Table 10. MCD mRNA expression in skeletal muscle.

\begin{tabular}{|c|c|c|c|c|c|}
\hline Sample & Group & $\mathrm{M} \pm \mathrm{SD}$ & Source & $\mathrm{F}$ & $\mathrm{p}$ \\
\hline \multirow{5}{*}{$\begin{array}{l}\text { Tibialis } \\
\text { anterior }\end{array}$} & $\mathrm{C}$ & $0.66 \pm 0.14$ & \multirow{5}{*}{$\begin{array}{l}\text { Exercise } \\
\text { Quercetin } \\
\text { Exercise } \times \text { Quercetin }\end{array}$} & \multirow{5}{*}{$\begin{array}{l}26.20 \\
0.14 \\
0.81\end{array}$} & \multirow{5}{*}{$\begin{array}{l}0.001 * * \\
0.72 \\
0.38\end{array}$} \\
\hline & Q & $0.70 \pm 0.24$ & & & \\
\hline & $\mathrm{F}$ & $036+000$ & & & \\
\hline & & $0.00+0.0$ & & & \\
\hline & EQ & $0.21 \pm 0.11$ & & & \\
\hline \multirow{5}{*}{ Soleus } & $\mathrm{C}$ & $2.10 \pm 1.10$ & \multirow{5}{*}{$\begin{array}{l}\text { Exercise } \\
\text { Quercetin } \\
\text { Exercise } \times \text { Quercetin }\end{array}$} & \multirow{5}{*}{$\begin{array}{l}0.95 \\
0.45 \\
0.23\end{array}$} & \multirow{5}{*}{$\begin{array}{l}0.35 \\
0.51 \\
0.64\end{array}$} \\
\hline & Q & $1.69 \pm 0.63$ & & & \\
\hline & $\mathrm{E}$ & $159+026$ & & & \\
\hline & $\mathrm{E}$ & $1.59 \pm 0.26$ & & & \\
\hline & EQ & $1.52 \pm 0.13$ & & & \\
\hline
\end{tabular}

** $\mathrm{p}<0.01$. C, High-fat for 12 weeks and low-fat diet for 8 weeks control; $\mathrm{Q}$, high-fat diet for 12 weeks and low-fat diet for 8 weeks with quercetin; E, high-fat diet for 12 weeks and low-fat diet for 8 weeks with exercise; EQ, high-fat diet for 12 weeks and low-fat diet for 8 weeks with exercise and quercetin. All values are expressed as means \pm standard deviations (SDs) of relative density units using $\beta$-actin as the control.

\section{ACC mRNA expression}

Exercise training had a significant effect on ACC mRNA expression in soleus muscle but quercetin supplementation did not. The interactions between exercise and quercetin treatment were not significantly different in ACC mRNA expression in tibialis anterior and soleus muscle (Table 11 and Fig. 4).

Table 11. ACC mRNA expression in skeletal muscle.

\begin{tabular}{lcclcc}
\hline Sample & Group & $\mathrm{M} \pm \mathrm{SD}$ & \multicolumn{1}{c}{ Source } & $\mathrm{F}$ & $\mathrm{p}$ \\
\hline & $\mathrm{C}$ & $0.29 \pm 0.04$ & & & \\
Tibialis & $\mathrm{Q}$ & $0.25 \pm 0.06$ & Exercise & 2.84 & 0.11 \\
anterior & $\mathrm{E}$ & $0.21 \pm 0.08$ & Quercetin & 0.21 & 0.66 \\
& $\mathrm{EQ}$ & $0.22 \pm 0.07$ & & & \\
\hline \multirow{5}{*}{ Soleus } & $\mathrm{C}$ & $0.83 \pm 0.06$ & & & \\
& $\mathrm{Q}$ & $0.76 \pm 0.12$ & Exercise & 26.59 & $.001^{* *}$ \\
& $\mathrm{E}$ & $0.61 \pm 0.09$ & Quercetin & 1.39 & 0.26 \\
& EQ & $0.59 \pm 0.07$ & & 0.66 & 0.43 \\
& & & & \\
\hline
\end{tabular}

** $\mathrm{p}<0.01$. C, High-fat for 12 weeks and low-fat diet for 8 weeks control; Q, high-fat diet for 12 weeks and low-fat diet for 8 weeks with quercetin; E, high-fat diet for 12 weeks and low-fat diet for 8 weeks with exercise; $\mathrm{EQ}$, high-fat diet for 12 weeks and low-fat diet for 8 weeks with exercise and quercetin. All values are means \pm standard deviations (SDs) of relative density units using $\beta$-actin as the control.

\section{SREBP-1 mRNA expression}

Exercise training had a significant effect on SREBP-1 mRNA expression in tibialis anterior and soleus muscle, whereas quercetin supplementation did not. The interactions between exercise and quercetin treatment were not significantly different in SREBP-1 mRNA expression in tibialis anterior and soleus muscle(Table 12, Fig. 4).
Table 12. Sterol regulatory element binding protein-1 (SREBP-1) mRNA expression of in skeletal muscle.

\begin{tabular}{|c|c|c|c|c|c|}
\hline Sample & Group & $\mathrm{M} \pm \mathrm{SD}$ & Source & $\mathrm{F}$ & $\mathrm{p}$ \\
\hline \multirow{4}{*}{$\begin{array}{l}\text { Tibialis } \\
\text { anterior }\end{array}$} & $\mathrm{C}$ & $1.20 \pm 0.31$ & \multirow{4}{*}{$\begin{array}{l}\text { Exercise } \\
\text { Quercetin } \\
\text { Exercise } \times \text { Quercetin }\end{array}$} & \multirow{4}{*}{$\begin{array}{l}4.80 \\
3.38 \\
2.11\end{array}$} & \multirow{4}{*}{$\begin{array}{l}0.05^{*} \\
0.09 \\
0.17\end{array}$} \\
\hline & Q & $0.73 \pm 0.07$ & & & \\
\hline & E & $0.68 \pm 0.46$ & & & \\
\hline & $F O$ & & & & \\
\hline \multirow{5}{*}{ Soleus } & $C$ & & \multirow{5}{*}{$\begin{array}{l}\text { Exercise } \\
\text { Quercetin } \\
\text { Exercise } \times \text { Quercetin }\end{array}$} & \multirow{5}{*}{$\begin{array}{l}32.99 \\
0.24 \\
1.27\end{array}$} & \multirow{5}{*}{$\begin{array}{l}.001^{* *} \\
0.63 \\
0.28\end{array}$} \\
\hline & $C$ & $1.00 \pm 0.06$ & & & \\
\hline & Q & $0.93 \pm 0.07$ & & & \\
\hline & E & $0.69 \pm 0.04$ & & & \\
\hline & EQ & $0.72 \pm 0.17$ & & & \\
\hline
\end{tabular}

$* \mathrm{p}<0.05, * * \mathrm{p}<0.01$. C, High-fat for 12 weeks and low-fat diet for 8 weeks control; Q, high-fat diet for 12 weeks and low-fat diet for 8 weeks with quercetin; E, high-fat diet for 12 weeks and low-fat diet for 8 weeks with exercise; EQ, high-fat diet for 12 weeks and low-fat diet for 8 weeks with exercise and quercetin. All values are means \pm standard deviations (SDs) of relative density units using $\beta$-actin as the control.

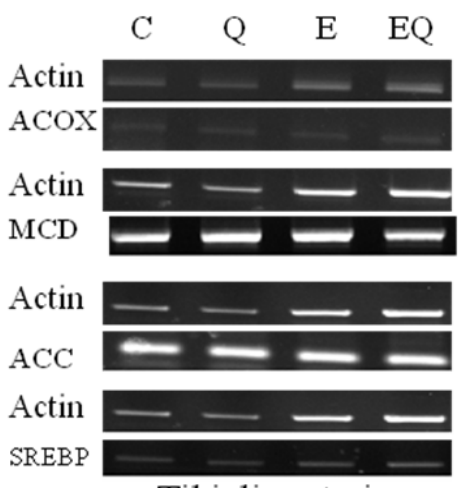

Tibialis anterior

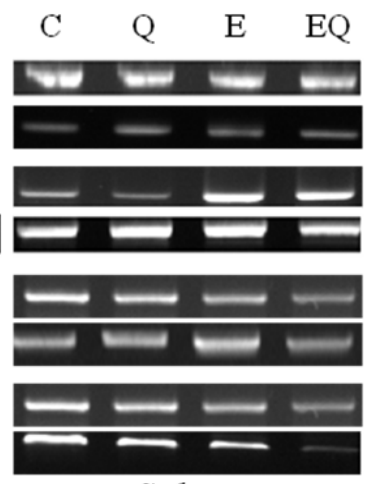

Soleus
Fig. 4. Reverse transcription polymerase chain reaction analysis of the expression of lipid metabolism markers in skeletal muscle.

\section{DISCUSSION}

Calorie restriction and exercise are both effective at improving insulin sensitivity and decreasing body weight, percent body fat, and inflammation [24-26]. The final body weights were significantly reduced in the three treatment groups compared to that in the control. Most of the dietary and exercise weight loss studies show the magnitude of decrease in inflammatory markers to be linearly related to the amount of weight lost [27]. Several markers of inflammation, including C-reactive protein, IL-6, TNF- $a$, and TNF- $a$ receptors decrease after weight loss achieved through shortterm intense dietary restriction [28]. Quercetin reduces macrophage expression of TNF- $a$, IL-1 $\beta$, and IL- 6 in a dosedependent manner by inhibiting lipopolysaccharide-induced expression of these pro-inflammatory cytokines [29]. The decrease in skeletal muscle inflammatory cytokines (IL-6, TNF-a, and MCP-1) in the Q group was influenced by 
quercetin intake. Nevertheless, quercetin (Q and $\mathrm{EQ}$ ) had no significant effect on inflammatory cytokine (IL-6, TNF-a, and MCP-1) expression in skeletal muscle.

Many studies have linked exercise to changes in cytokine levels. Regular physical activity results in a reduced inflammatory state, Pedersen [30], suggested that regular exercise modulates some pro-and anti-inflammatory cytokines, induces suppression of TNF- $a$ and thereby offers protection against exacerbated inflammation. In contrasts, strenuous exercise induces an increase in the pro-inflammatory cytokines TNF-a and IL-1 $\beta$ and a dramatic increase in the inflammation responsive cytokine IL-6 [31]. We showed that moderate exercise after strenuous exercise with weight loss decreased IL-6, TNF-a, and MCP-1 mRNA expression in the tibialis anterior muscle. Additionally, TNF- $a$, and MCP-1 showed decreased mRNA expression in soleus muscle. There is controversy regarding skeletal muscle fiber types and production of IL-6 [32], as IL-6 accumulates equally in both type 1 and type 2 fibers.

Our results on IL-6 levels are in agreement with those reported after long-term antioxidant supplementation in individuals performing moderate exercise [33], indicating that moderate antioxidant supplementation does not affect immune adaptive mechanisms of long-term exercise.

PGC-1a plays an important role stimulating mitochondrial biogenesis following physiological demands and nutritional input, such as exercise or the dietary flavonoid resveratrol $[34,35]$. Endurance exercise induces an increase in muscle mitochondria [36]. A single bout of exercise stimulates mitochondrial biogenesis, as evidenced by increases in the expression of mitochondrial proteins [37]. The mechanism by which an increase in muscle mitochondria increases exercise capacity and endurance is by reducing the disturbance in metabolic homeostasis during sub-maximal exercise. Repeated bouts of exercise maintain this effect. Endurance exercise induces an increase in PGC-1a protein content in the nucleus without causing any change in the total PGC-1a protein level immediately after 2 hours of swimming in rats [38]. In this study, the exercise group showed increased the PGC-1 expression in skeletal muscle. Nevertheless, there was not main effect of exercise training ( $E$ and $E Q$ ).

Exercise increases the expression and function of Tfam in muscle in both animals and humans. One week of chronic contractile activity of rat muscle led to an increase in Tfam mRNA level after 4 days, an accelerated protein import into the matrix, an increase in Tfam-mtDNA binding and elevated mtDNA transcript levels encoding cytochrome $c$ oxidase (COX) subunit III, and a higher COX enzyme activity by day 7 [39]. An increase in Tfam mRNA levels indicates that mitochondrial biogenesis responded to exercise; however, the lack of change in mitochondrial subunits indicates that the mitochondrial biogenesis response may have been blocked downstream of Tfam. In the present study, the main effect of endurance exercise training for the fast-twitch tibialis anterior muscle was a tendency to increase the mitochondrial biogenesis (PGC-1 and Tfam) as well as in the slow-twitch soleus muscle.

These findings suggest that the mechanisms regulating the moderate exercise-induced activation of PGC-1 and Tfam mRNA expression in muscle may be adaptive to exercise with endurance exercise.

Previous research examining the effect of polyphenols supplementation showed significantly up-regulated the acylCoA oxidase (ACO) mRNA level in epididymal fat [40]. In our study, quercetin group showed increased ACOX expression in skeletal muscle. Nevertheless, there was no main effect of the quercetin group (Q and EQ). However, there was a main effect of the exercise group (E and $E Q$ ).

Voluntary treadmill running exercise increase only AMPK2 activity in rat skeletal muscle, which is accompanied by increased glucose transport and ACC phosphorylation [41]. The net effect of these changes in kinetic properties is a decrease in ACC activity (i.e., lower rate of malonyl-CoA synthesis), particularly at citrate concentrations found in the muscle. SREBP-1 is a proximal transcription factor that increases lipogenic capacity, because it can be up-regulated by hyperinsulinemia induced by over-nutrition [42].

Previous research examined the effect of a single bout of exercise on up-regulating SREBP-1c [43]. According to research by Pawel et al. [44], SREBP-1c expression and SREBP-1 protein levels are not affected by exercise training. In our study, the exercise group showed increased SREBP-1 expression in skeletal muscle.

The exercise groups (E and EQ) had significant differences in lipolysis (ACOX) and lipogenesis (MCD and SREBP-1) gene expression in tibialis anterior muscle. Additionally, the exercise groups (E and $\mathrm{EQ}$ ) showed significant differences in lipogenesis (MCD and SREBP-1) expression in soleus muscle. Exercise reduced lipogenesis and increased lipolysis. These results show differences between type I and type II muscles.

In conclusion, during the training period, muscles experienced changes in mRNA expression that brought about adaptation to aerobic exercise. Therefore, we believe that the strenuous exercise caused less metabolic stress in the exercise group, as indicated by the lack of an increase in ACOX mRNA in response to the strenuous exercise. Exercise (moderate and strenuous exercise) plays an important role 
increasing fatty acids and decreasing fatty acid synthesis; thereby, decreasing body weight benefiting lipid metabolism.

\section{ACKNOWLEDGEMENTS}

This work was supported by research fund of Chungnam National University.

All experiments were approved by the Animal Care and Use Committee at the Chungnam National University (CNU-00202).

\section{REFERENCES}

[1] Woods SC, Seeley RJ, Rushing PA, D'Alessio D, Tso P. A controlled high-fat diet induces an obese syndrome in rats. J Nutr. 2003;133:1081-1087.

[2] Tripathy D, Mohanty P, Dhindsa S, Syed T, Ghanim H, Aljada A, Dandona P. Elevation of free fatty acids induces inflammation and impairs vascular reactivity in healthy subjects. Diabetes. 2003;52:2882-2897.

[3] Hotamisligil GS, Arner P, Caro JF, Atkinson RL, Spiegelman BM. Increased adipose tissue expression of tumor necrosis factor-in human obesity and insulin resistance. J Clin Invest. 1995;95:2409-2415.

[4] Heo HJ, Lee CY. Protective effects of quercetin and vitamin $\mathrm{C}$ against oxidative stress-induced neurodegeneration. J Agric Food Chem. 2004;52(25):7514-7517.

[5] Nair MP, Mahajan JL, Reynolds R, Aalinkeel H, Nair SA, Kandaswami C. The flavonoid quercetin inhibits proinflammatory cytokine (tumor necrosis factor alpha) gene expression in normal peripheral blood mononuclear cells via modulation of the NF-kB system. Clin. Vaccine Immunol. 2006;13:319-328.

[6] Chiang LC, Chiang W, Liu MC, Lin CC. In vitro antiviral activities of Caesalpinia pulcherrima and its related flavonoids. J. Antimicrob. Chemother. 2003;52: 194-198.

[7] Comalada M, Ballester I, Bailon E, Sierra S, Xaus J, Galve J, de Medina FS, Zarzuelo A. Inhibition of proinflammatory markers in primary bone marrow-derived mouse macrophages by naturally occurring flavonoids: analysis of the structure-activity relationship. Biochem Pharmacol. 2006;72:1010-1021.

[8] Gleeson M. Immune function in sport and exercise. J Appl Physiol. 2007;103(2):693-699.

[9] Pedersen BK, Anders DT. Effects of exercise on the lymphocytes and cytokines. Br J Sports Med. 2000;34:
246-251.

[10] Fischer CP, Hiscock NJ. Supplementation with vitamins $\mathrm{C}$ and $\mathrm{E}$ inhibits the release of interleukin- 6 from contracting human skeletal muscle. J Physiol. 2004;558(2): 633-645.

[11] Petersen AM, Pedersen BK. The role of IL-6 in mediating the anti-inflammatory effects of exercise. J Physiol Pharmacol. 2006;57(10): 43-51

[12] Lauren MS, Hui X, Robert AK, Randall M, Matthew WH, George AB, Steven RS. A High-Fat Diet Coordinately Downregulates Genes Required for Mitochondrial Oxidative Phosphorylation in Skeletal Muscle. Diabetes. 2005;54:1926-1933.

[13] Sparks LM, Xie H, Koza RA, Mynatt R, Hulver MW, Bray GA. et al. A high-fat diet coordinately downregulates genes required for mitochondrial oxidative phosphorylation in skeletal muscle. Diabetes. 2005;54(7): 1926-1933.

[14] Puigserver P, Spiegelman BM. Peroxisome proliferatoractivated receptor-gamma coactivator 1 alpha (PGC-1 alpha): transcriptional coactivator and metabolic regulator. Endocr Rev. 2003;24(1):78-90.

[15] Ahn J, Cho I, Kim S, Kwon D, Ha T. Dietary resveratrol alters lipid metabolism-related gene expression of mice on an atherogenic diet. J. Hepatol. 2008;49:1019-1028.

[16] Trumbeckaite S, Bernatoniene J, Majiene D, Jakstas V, Savickas A, Toleikis A. The effect of flavonoids on rat heart mitochondrial function. Biomed Pharmacother. 2006; 60:245-248

[17] Grinton S, Powers SK, Lawler J, Criswell D, Dodd S \& Edwards W. Endurance training-induced increases in expiratory muscle oxidative capacity. Med Sci Sports Exerc. 1992;24:551-555.

[18] Hara K, Tobe K, Okada T, Kadowaki H, Akanuma Y, Ito $\mathrm{C}$, Kimura $\mathrm{S}$, Kadowaki T. A genetic variation in the PGC-1 gene could confer insulin resistance and susceptibility to Type II diabetes. Diabetologia. 2002;45:740-743.

[19] Goto M, Terada S, Kato M, Katoh M, Yokozeki T, Tabata I \& Shimokawa T. cDNA cloning and mRNA analysis of PGC-1 in epitrochlearis muscle in swimmingexercised rats. Biochem Biophys Res Commun. 2000; 274:350-354.

[20] Yu R, Kim CS, Kwon BS, Kawada T. Mesenteric adipose tissue-derived monocyte chemoattractant protein-1 plays a crucial role in adipose tissue macrophage migration and activation in obese mice. Obesity. 2006;14:13531362

[21] Spina RJ, Chi MM, Hopkins MG, Nemeth PM, Lowry $\mathrm{OH}$, Holloszy JO. Mitochondrial enzymes increase in 
muscle in response to 7-10 days of cycle exercise. Journal of Applied Physiology. 1996;80:2250-2254.

[22] McGarry JD, Mannaerts GP, Foster DW. A possible role for malonyl-CoA in the regulation of hepatic fatty acid oxidation and ketogenesis. J. Clin. Invest. 1977;60:265270.

[23] Schefer V, Talan MI. Oxygen consumption in adult and aged C57BL/6J mice during acute treadmill exercise of different intensity. Exp. Gerontol. 1996;31,387-392.

[24] Weiss. Personality and Subjective Well-Being in Orangutans. Journal of Personality and Social Psychology. 2006; 90(3):501-551.

[25] Jeong JH, Park HG, Lee YR, Kwon SM, Jang HY, Jun JK, Kim MH, Lee SK, Lee KM, Lee WL. Effect of moderate exercise training and low-fat diet on peritoneal macrophage immunocompetence in high-fat diet induced obese mice model. J Exerc Nutr Biochem. 2012;16(3): 133-142.

[26] Park HG, Jung DJ, Jeong JH, Jun JK, Yoon AR, Lee YR, Min KE, Kim MH, Lee KM, Lee WL. Aerobic exercise training enhances cell proliferation and reduces IL-2 and IL-6 cytokine production in spleen of high fat diet-induced obese mice. J Exerc Nutr Biochem. 2013; 17(1):7-13.

[27] Woods SC, Seeley RJ, Rushing PA, D'Alessio D, Tso P. A controlled high-fat diet induces an obese syndrome in rats. J Nutr. 2003;133:1081-1087.

[28] Xydakis AM, Case CC, Jones PH, Hoogeveen RC, Liu MY, Smith EO, et al. Adiponectin, inflammation, and the expression of the metabolic syndrome in obese individuals: the impact of rapid weight loss through caloric restriction. J Clin Endocrinol Metab. 2004;89: 2697-2703.

[29] Cho SY, Park SJ, Kwon MJ, Jeong TS, Bok SH, Choi WY. et al. Quercetin suppresses proinflammatory cytokines production through MAP kinases and NF-kappaB pathway in lipopolysaccharide-stimulated macrophage. Mol Cell Biochem. 2003;243:153-160.

[30] Pedersen BK. The anti-inflammatory effect of exercise: its role in diabetes and cardiovascular disease control. Essays Biochemistry. 2006;42:105-117.

[31] Ostrowski K, Rohde T, Asp S, Schjerling P, Pedersen BK. The cytokine balance and strenuous exercise: TNF alpha, IL-2beta, IL-6, IL-1ra, sTNF-r1, sTNF-r2, and IL-10. J Physiol (Lond). 1999;515:287-291.

[32] Penkowa M, Keller C, Keller P, Jauffred S, Pedersen BK. Immunohistochemical detection of interleukin-6 in human skeletal muscle fibres following exercise. FASEB J. 2003;17:2166-2168.
[33] Phillips T, Childs AC et al. A dietary supplement attenuates IL-6 and CRP after eccentric exercise in untrained males. Med Sci Sports Exerc. 2003;35(12): 2032-2037.

[34] Csiszar A, Labinskyy N, Pinto JT, Ballabh P, Zhang H, Losonczy $\mathrm{G}$ et al. Resveratrol induces mitochondrial biogenesis in endothelial cells. Am J Physiol Heart Circ Physiol. 2009;297:H13-H20.

[35] Lagouge M, Argmann C, Gerhart-Hines Z, Meziane H, Lerin C, Daussin F, Messadeq N, Milne J, Lambert P, Elliott P, Geny B, Laakso M, Puigserver P, Auwerx J. Resveratrol improves mitochondrial function and protects against metabolic disease by activating SIRT1 and PGC-1alpha. Cell. 2006;127:1109-1122.

[36] Calvo JA, Daniels TG, Wang X, Paul A, Lin J, Spiegelman BM, Stevenson SC, Rangwala SM. Muscle-specific expression of PPARgamma coactivator-1alpha improves exercise performance and increases peak oxygen uptake. J Appl Physiol. 2008;104:1304-1312.

[37] Irrcher I, Adhihetty PJ, Sheehan T, Joseph AM, Hood DA. PPARgamma coactivator-1alpha expression during thyroid hormone- and contractile activity-induced mitochondrial adaptations. Am. J. Physiol. Cell Physiol. 2003;284: C1669-C1677.

[38] Wright DC, Han DH, Garcia-Roves PM, Geiger PC, Jones TE, Holloszy JO. Exercise-induced mitochondrial biogenesis begins before the increase in muscle PGC-1a expression. J Biol Chem. 2007;282:194-199.

[39] Gordon JW, Rungi AA, Inagaki H, Hood DA. Effects of contractile activity on mitochondrial transcription factor A expression in skeletal muscle. J. Appl. Physiol. 2001;90:389-396.

[40] Yoshiko F, Masanori H, Miki O, Sanae H, Yuka N, Toshihiko O, Michka N. Lemon polyphenols suppress diet induced obesity by up-regulation of mRNA levels of the enzymes involved in $\beta$-oxidation in mouse white adipose tissue. J. Clin. Biochem. Nutr. 2008;43:201-209.

[41] Vavvas D, Apazidis A, Saha AK, Gamble J, Patel A, Kemp BE, Witters LA, and Ruderman NB. Contractioninduced changes in acetyl-CoA carboxylase and 5-AMPactivated kinase in skeletal muscle. J Biol Chem. 1997; 272:13255-13261.

[42] Winder WW, Hardie DG. Inactivation of acetyl-CoA carboxylase and activation of AMP-activated protein kinase in muscle during exercise. Am. J. Physiol. 1996;270: E299-304.

[43] Kim JB, Sarraf P, Wright M, Yao KM, Mueller E, Solanes G, Lowell BB, Spiegelman BM. Nutritional and insulin regulation of fatty acid synthetase and leptin gene 
expression through ADD1/SREBP1. J. Clin. Invest. 1998; 101:1-9.

[44] Pawel D, Aleksandra P, Magdalena J, Konrad S, Jozef L, Agnieszka D. Endurance training-induced accumu- lation of muscle triglycerides is coupled to upregulation of stearoyl-CoA desaturase 1. Journal of Applied Physiology. 2010;6:1653-1661. 